\title{
Short communication: Characterization of methicillin-resistant Staphylococcus aureus isolated from raw milk fresh cheese in Colombia
}

\author{
Fanny C. Herrera, ${ }^{*} \dagger$ María-Luisa García-López, ${ }^{*}$ and Jesús A. Santos ${ }^{* 1}$ \\ *Department of Food Hygiene and Food Technology, Veterinary Faculty, University of León, ES24071 Spain \\ †Grupo de Investigación en Microbiología y Biotecnología (GIMBIO), Departamento de Microbiología, Facultad de Ciencias Básicas, \\ Universidad de Pamplona, Pamplona, Norte de Santander, Colombia
}

\begin{abstract}
The aim of this study was the characterization of a collection of 8 methicillin-resistant Staphylococcus aureus (MRSA) isolates, obtained from samples of fresh cheese (Doble Crema) produced from raw cow milk in small dairies in Colombia. All the isolates harbored the $m e c A$ and Panton-Valentine leukocidin (PVL) genes, presented with SCCmec type IV, and belonged to multilocus sequence type 8 and spa type 024. Seven isolates presented 3 closely related pulsed-field gel electrophoresis profiles. Three of them carried the staphylococcal enterotoxin B gene. The isolates were resistant to cefoxitin, oxacillin, penicillin, and ampicillin and susceptible to all non- $\beta$-lactams antibiotics tested, with minimum inhibitory concentration values for oxacillin of 4 to $8 \mathrm{mg} / \mathrm{L}$. The isolates belonged to the community-acquired MRSA group, suggesting a human source of contamination. The risk of human infection by MRSA via contaminated foods is considered low, but contaminated food commodities can contribute to the worldwide dissemination of clones of communityacquired MRSA.
\end{abstract}

Key words: methicillin-resistant Staphylococcus aureus, MRSA, Doble Crema cheese

\section{Short Communication}

Methicillin-resistant Staphylococcus aureus (MRSA) is a microorganism of concern as an important cause of nosocomial infections (hospital-associated MRSA). In recent years, the appearance of cases outside the hospital environment has put the focus in the so-called community-associated or community-acquired MRSA strains (CA-MRSA). The CA-MRSA are considered a serious threat to public health because they can be easily spread through healthy carriers and they present additional virulence factors that make them more

Received April 15, 2016.

Accepted June 8, 2016.

${ }^{1}$ Corresponding author: j.santos@unileon.es likely to cause disease (Weber, 2005). The CA-MRSA strains generally carry the Panton-Valentine leukocidin (PVL) gene, staphylococcal chromosomal cassette mec (SCC mec) type IV, and are susceptible to antimicrobials other than $\beta$-lactams (Vandenesch et al., 2003). The third significant type of MRSA is associated with livestock animals, which was initially detected in swine farms in Europe and now is distributed worldwide and has spread to humans and other animal species. Most livestock-associated MRSA isolates are resistant to tetracyclines and do not carry either the PVL gene or staphylococcal enterotoxin (SE) genes (EFSA, 2009; Doyle et al., 2011).

Even though the isolation of MRSA from livestock and foods of animal origin has been reported extensively, the effect of MRSA in food-related illness is very low. To date, only 2 outbreaks of MRSA involving food have been reported (Kluytmans et al., 1995; Jones et al., 2002). However, there are some concerns whether food can constitute a reservoir of MRSA and food handlers can become infected with MRSA via food manipulation (EFSA, 2009; Doyle et al., 2011).

The prevalence of MRSA in cattle appears to be low (Alves et al., 2009), but there are reports of isolation of MRSA as an agent of intramammary infection (Lee, 2006; Luini et al., 2015) and also from bulk tank milk and dairy products (Normanno et al., 2007; Virgin et al., 2009; Can and Çelik, 2012). Strains of MRSA are disseminated worldwide and $S$. aureus remains as an important foodborne pathogen in Latin America (Pires et al., 2012); however, studies on the prevalence of MRSA in food commodities in Latin America are scarce (Rizek et al., 2011; Vanegas López et al., 2012). In a study carried out in Colombia by Vanegas-López et al. (2012), they identified 5 MRSA strains (one of them from milk cream) among 149 isolates.

Doble Crema (double cream) cheese is one of the most popular cheeses in Colombia, accounting for more than $30 \%$ of total cheese consumption. It is a fresh cheese similar to mozzarella and other stretched curd cheeses and traditionally made from raw cow milk in small dairies in Colombia. In research carried out on 
Doble Crema cheese, we characterized 65 isolates of coagulase-positive staphylococci and $18.5 \%$ of them were MRSA carrying the mecA gene (Herrera and Santos, 2015a,b). The aim of this study was to characterize the collection of $8 \mathrm{MRSA}$ isolates by genetic typing and antimicrobial susceptibility testing.

The isolates were obtained from samples of raw milk cheese (Doble Crema cheese) collected at the retail level between April 2012 and April 2013 and identified as coagulase-positive staphylococci and MRSA as previously described (Herrera and Santos, 2015a,b). Briefly, $S$. aureus counts were determined on Baird Parker agar with egg yolk-tellurite (Oxoid, Basingstoke, UK) and up to 3 typical colonies were confirmed as coagulasepositive by coagulase test (Lancette and Bennet, 2001). Isolates from 8 cheese samples carried the mecA gene and were considered as MRSA. Bacterial strains were preserved at $-80^{\circ} \mathrm{C}$ in brain heart infusion (BHI; Oxoid) broth plus $30 \%$ glycerol and routinely cultured in BHI broth at $37^{\circ} \mathrm{C}$.

Antimicrobial susceptibility testing of the isolates was performed using the disk diffusion method recommended by EUCAST (www.eucast.org) against the following antimicrobials: cefoxitin, oxacillin, penicillin, ampicillin, gentamicin, ciprofloxacin, levofloxacin, norfloxacin, ofloxacin, teicoplanin, vancomycin, clindamycin, azithromycin, clarithromycin, erythromycin, chloramphenicol, nitrofurantoin, rifampicin, trimethoprim-sulfamethoxazole, trimethoprim, and tetracycline, using S. aureus CECT 794 as the control strain. Isolates were classified as susceptible or resistant according to the EUCAST breakpoint Table 2016 v6.0. Minimum inhibitory concentration values for oxacillin were determined with M.I.C. Evaluator strips (Oxoid) according to the manufacturer's instructions.

Amplification of genes responsible for production of selected enterotoxins (SEA, SEB, SEC, SED, SEE, SEG, SEH, and SEI), resistance to methicillin (mecA and mecC), production of PVL $(l u k S / F)$, and the presence of the $\operatorname{arcA}$ gene of the arginine catabolic mobile element (ACME) was carried out from a fresh culture of each isolate. An aliquot of $1 \mathrm{~mL}$ was centrifuged and the pellet was treated with $200 \mu \mathrm{L}$ of InstaGene matrix (Bio-Rad, Hercules, CA) to release the DNA. Primers and conditions of the PCR protocols were described elsewhere (Lina et al., 1999; Smyth et al., 2001; Jarraud et al., 2002; Diep et al., 2008; García-Álvarez et al., 2011).

The SCCmec type was determined by the multiplexPCR procedure described by Boye et al. (2007). The spa type was established by amplifying and sequencing the spa gene (Shopsin et al., 1999) and sequences were analyzed with spaTyper (http://spatyper.fortinbras. us/). Pulsed-field gel electrophoresis (PFGE) was carried out as described by McDougal et al. (2003). Comparison of profiles was done with the GelCompar 6.5 software (Applied Maths, St. Martens Latem, Belgium). Similarities were obtained using the Dice coefficient at $0.5 \%$ optimization and $1.25 \%$ tolerance, and a dendrogram was constructed with the unweighted-pair group method using the arithmetic mean clustering method. Multilocus sequence typing was performed following the procedure of Enright et al. (2000), and the allele number and sequence type of the isolates were assigned by comparison with data available in the multilocus sequence typing database (http://saureus.beta. mlst.net/).

The 8 isolates were resistant to cefoxitin $(30 \mu \mathrm{g})$, oxacillin $(1 \mu \mathrm{g})$, and the $\beta$-lactam antibiotics and susceptible to all non- $\beta$-lactam antibiotics tested. The MIC values for oxacillin were $4 \mathrm{mg} / \mathrm{L}$ for 6 isolates (FH 30, FH 32, FH 34, FH 44, FH 65, and FH 67) and $8 \mathrm{mg} / \mathrm{L}$ for 2 isolates ( $\mathrm{FH} 38$ and $\mathrm{FH} 61$ ), which are values that allow classification of isolates as MRSA. All the isolates harbored the mecA and the PVL $l u k \mathrm{~S} /$ $l u k \mathrm{~F}$ genes, which are characteristic features of the CAMRSA group (Vandenesch et al., 2003). The mecC gene was not detected in any MRSA isolate; this homolog of $m e c A$ was reported recently (García-Álvarez et al., 2011) and few studies are available on the prevalence of mecC in humans and animals (Diaz et al., 2016). Strains carrying the $m e c C$ gene have been isolated from cattle in different European countries, but not on the American continent; however, it is advisable to check for its presence to monitor its dissemination over time and to discover potential animal reservoirs (GarcíaÁlvarez et al., 2011; Petersen et al., 2013; Ariza-Miguel et al., 2014; Diaz et al., 2016).

Genetic typing revealed that the isolates presented with the same SCCmec type IV and belonged to sequence type 8 and spa type t024, related to the USA300 type, the predominant cause of CA-MRSA infection in the United States (Tenover and Goering, 2009), which is disseminated in Latin America, particularly in Colombia (Reyes et al., 2009; Márquez-Ortiz et al., 2014). The isolates we studied failed to amplify the $\operatorname{arc} A$ gene, an ACME-specific gene often found in USA300 isolates (Planet et al., 2013), but that seems to be absent in the Latin American strains (Márquez-Ortiz et al., 2014; Hidalgo et al., 2015). Moreover, USA300 isolates are showing increasing tetracycline resistance (Tenover and Goering, 2009), which can be related to the presence of ACME (Planet et al., 2013), thus explaining the lack of tetracycline resistance found in our isolates and in other studies carried out with USA300-related strains isolated in Colombia (Hidalgo et al., 2015). 

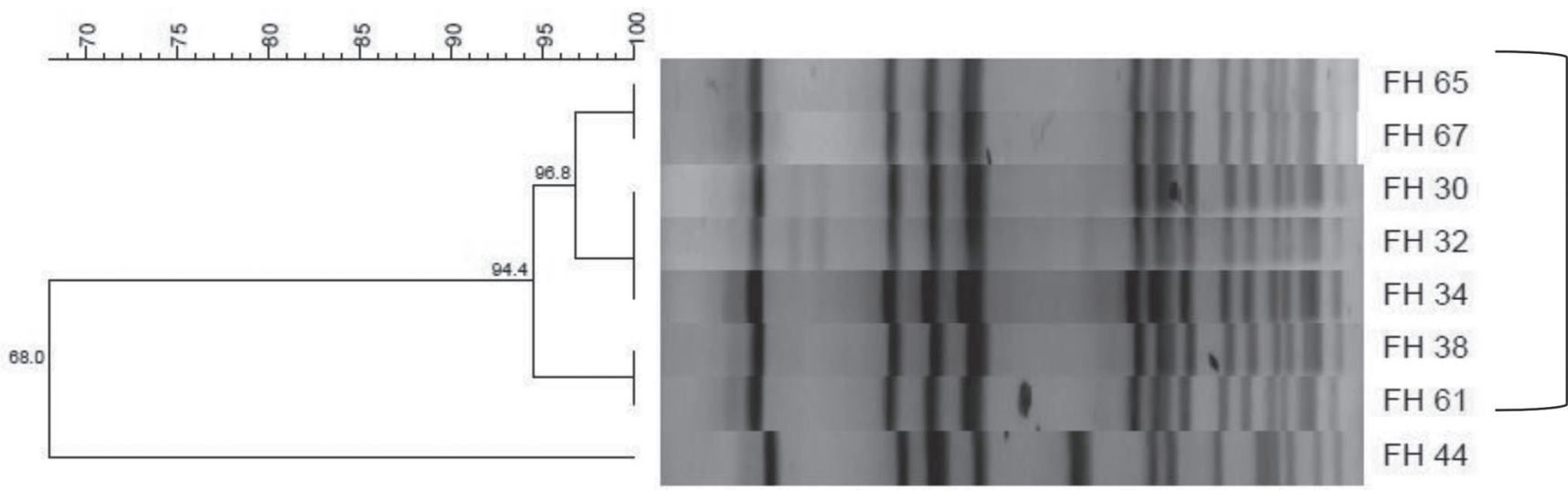

A

Figure 1. Dendrogram showing the similarities between pulsed-field gel electrophoresis profiles (clusters A and B) of methicillin-resistant Staphylococcus aureus isolates using the Dice coefficient and unweighted-pair group method using arithmetic mean.

Seven isolates (FH 65-FH 67, FH 30-FH 32-FH 34, and FH 38-FH 61) presented 3 closely related PFGE profiles with $94.4 \%$ similarity, whereas isolate $\mathrm{FH} 44$ presented a different band pattern (Figure 1). Visual comparison of pulsotypes showed similarities with those obtained by Márquez-Ortiz et al. (2014) among Colombian pediatric patients.

Three isolates (FH 61, FH 65, and FH 67) carried the SEB gene. The presence of genes responsible for SE production in food isolates of MRSA has been described by other authors (Normanno et al., 2007; Can and Çelik, 2012) and there is a reported outbreak of foodborne intoxication due to an enterotoxigenic strain of MRSA producing SEC (Jones et al., 2002). Methicillin-resistant $S$. aureus is a pathogen of concern due to the severity of the illnesses caused and its worldwide spread. Its presence in foods of animal origin adds additional threats, as it may cause staphylococcal intoxication if the strains are able to produce enterotoxin, and may contribute to the dissemination along the food chain (Doyle et al., 2011). On the other hand, the SEB is a toxin type rarely associated with staphylococcal food poisoning (Seo and Bohach, 2013). The characteristics of the isolates are summarized in Table 1.

The results of the present study show the presence of USA300-related strains of CA-MRSA in Doble Crema cheese, indicating a human source of contamination. Transmission of MRSA strains between farm workers and farm animals has been reported (Juhász-Kaszanyitzky et al., 2007; Lim et al., 2013) and also between food handlers and foods (Jones et al., 2002). The risk of human infection by MRSA via contaminated foods is considered low (EFSA, 2009), but food-related outbreaks of MRSA infection and intoxication have been reported (Kluytmans et al., 1995; Jones et al., 2002) and contaminated food commodities can contribute to the worldwide dissemination of clones of CA-MRSA (Ogata et al., 2012; Rodríguez-Lázaro et al., 2015). Improved hygienic measures in food processing plants are needed to ensure the microbiological safety of foods. More studies must be conducted to identify the sources of contamination and to implement control mechanisms.

Table 1. Genetic characteristics of methicillin-resistant Staphylococcus aureus (MRSA) isolates ${ }^{1}$

\begin{tabular}{lccccccc}
\hline Isolate & mecA & PVL & Enterotoxin gene & SCCmec type & PFGE cluster & MLST type & spa type \\
\hline FH 30 & + & + & - & IV & A & 8 & t024 \\
FH 32 & + & + & - & IV & A & 8 & 024 \\
FH 34 & + & + & - & IV & A & 8 & t024 \\
FH 38 & + & + & - & IV & A & 8 & 024 \\
FH 44 & + & + & - & IV & B & 8 & t024 \\
FH 61 & + & + & SEB & IV & A & 8 & 024 \\
FH 63 & + & + & SEB & IV & A & 8 & t 024 \\
FH 65 & + & + & SEB & IV & A & 8 & 024 \\
FH 67 & + & + & SEB & IV & A & 8 & t024 \\
\hline
\end{tabular}

${ }^{1} \mathrm{PVL}=$ Panton-Valentine leukocidin; PFGE $=$ pulsed-field gel electrophoresis; MLST $=$ multilocus sequence typing. 


\section{ACKNOWLEDGMENTS}

Fanny C. Herrera acknowledges an allowance from the Department of Microbiology, Faculty of Basic Science, University of Pamplona, Spain, to carry out the research at the University of León.

\section{REFERENCES}

Alves, P. D. D., J. A. McCulloch, S. Even, C. Le Maréchal, A. Thierry, N. Grosset, V. Azevedo, C. A. Rosa, E. Vautor, and Y. Le Loir. 2009. Molecular characterisation of Staphylococcus aureus strains isolated from small and large ruminants reveals a host rather than tissue specificity. Vet. Microbiol. 137:190-195.

Ariza-Miguel, J., M. Hernández, I. Fernández-Natal, and D. RodríguezLázaro. 2014. Methicillin-resistant Staphylococcus aureus harboring mecC in livestock in Spain. J. Clin. Microbiol. 52:4067-4069.

Boye, K., M. D. Bartels, I. S. Andersen, J. A. Møller, and H. Westh. 2007. A new multiplex PCR for easy screening of methicillin-resistant Staphylococcus aureus SCCmec types I-V. Clin. Microbiol. Infect. 13:725-727.

Can, H. Y., and T. H. Çelik. 2012. Detection of enterotoxigenic and antimicrobial resistant $S$. aureus in Turkish cheeses. Food Contr. 24:100-103.

Diaz, R., E. Ramalheira, V. Afreixo, and B. Gago. 2016. Methicillinresistant Staphylococcus aureus carrying the new mecC gene-A meta-analysis. Diagn. Microbiol. Infect. Dis. 84:135-140.

Diep, B. A., G. G. Stone, L. Basuino, C. J. Graber, A. Miller, S.A. des Etages, A. Jones, A. M. Palazzolo-Ballance, F. PerdreauRemington, G. F. Sensabaugh, F. R. DeLeo, and H. F. Chambers. 2008. The arginine catabolic mobile element and staphylococcal chromosomal cassette mec linkage: Convergence of virulence and resistance in the USA300 clone of methicillin-resistant Staphylococcus aureus. J. Infect. Dis. 197:1523-1530.

Doyle, M. E., F. A. Hartmann, and A. C. L. Wong. 2011. White paper on sources of methicillin-resistant Staphylococcus aureus (MRSA) and other methicillin-resistant staphylococci: Implications for our food supply. Food Res. Institute, University of Wisconsin-Madison.

EFSA. 2009. Scientific Opinion of the Panel on Biological Hazards on a request from the European Commission on assessment of the public health significance of methicillin resistant Staphylococcus aureus (MRSA) in animals and foods. EFSA J. 993:1-73.

Enright, M. C., N. P. Day, C. E. Davies, S. J. Peacock, and B. G. Spratt. 2000. Multilocus sequence typing for characterization of methicillin-resistant and methicillin-susceptible clones of Staphylococcus aureus. J. Clin. Microbiol. 38:1008-1015.

García-Álvarez, L., M. T. G. Holden, H. Lindsay, C. R. Webb, D. F. J. Brown, M. D. Curran, E. Walpole, K. Brooks, D. J. Pickard, C. Teale, J. Parkhill, S. D. Bentley, G. F. Edwards, E. K. Girvan, A. M. Kearns, B. Pichon, R. L. R. Hill, A. R. Larsen, R. L. Skov, S. J. Peacock, D. J. Maskell, and M. a. Holmes. 2011. Meticillinresistant Staphylococcus aureus with a novel mecA homologue in human and bovine populations in the UK and Denmark: A descriptive study. Lancet Infect. Dis. 11:595-603.

Herrera, F. C., and J. A. Santos. 2015a. Enterotoxigenic genes in strains of Staphylococcus spp., isolated from cheese made in Pamplona-Colombia. Rev MVZ Cordoba 19:4472-4481.

Herrera, F. C., and J. A. Santos. 2015b. Presencia de Staphylococcus aureus meticilina-resistentes en queso doble crema artesanal. Rev. U.D.C.A Actual. Divulg. Científica 18:29-37.

Hidalgo, M., L. P. Carvajal, S. Rincón, Á. A. Faccini-Martínez, A. A. Tres Palacios, M. Mercado, S. L. Palomá, L. X. Rayo, J. A. Acevedo, J. Reyes, D. Panesso, P. García-Padilla, C. Alvarez, and C. A. Arias. 2015. Methicillin-resistant Staphylococcus aureus USA300 Latin American variant in patients undergoing hemodialysis and HIV infected in a hospital in Bogotá, Colombia. PLoS ONE 10:e0140748.
Jarraud, S., C. Mougel, J. Thioulouse, G. Lina, H. Meugnier, F. Forey, X. Nesme, J. Etienne, and F. Vandenesch. 2002. Relationships between Staphylococcus aureus genetic background, virulence factors, agr groups (alleles), and human disease. Infect. Immun. 70:631-641.

Jones, T. F., M. E. Kellum, S. S. Porter, M. Bell, and W. Schaffner. 2002. An outbreak of community-acquired foodborne illness caused by methicillin-resistant Staphylococcus aureus. Emerg. Infect. Dis. 8:82-84.

Juhász-Kaszanyitzky, É., S. Jánosi, P. Somogyi, Á. Dán, L. van der Graaf-vanBloois, E. Van Duijkeren, and J. A. Wagenaar. 2007. MRSA transmission between cows and humans. Emerg. Infect. Dis. 13:630-632.

Kluytmans, J., W. van Leeuwen, W. Goessens, R. Hollis, S. Messer, L. Herwaldt, H. Bruining, M. Heck, J. Rost, and N. van Leeuwen. 1995. Food-initiated outbreak of methicillin-resistant Staphylococcus aureus analyzed by pheno- and genotyping. J. Clin. Microbiol. $33: 1121-1128$.

Lancette, G. A., and R. W. Bennet. 2001. Staphylococcus aureus and staphylococcal enterotoxins. Pages 387-403 in Compendium of Methods for the Microbiological Examination of Foods. F. P. Downes and K. Ito, ed. APHA, Washington, DC.

Lee, J. H. 2006. Occurrence of methicillin-resistant Staphylococcus aureus strains from cattle and chicken, and analyses of their mecA, mecR1 and mecI genes. Vet. Microbiol. 114:155-159.

Lim, S.-K., H.-M. Nam, G.-C. Jang, H.-S. Lee, S.-C. Jung, and T.-S. Kim. 2013. Transmission and persistence of methicillin-resistant Staphylococcus aureus in milk, environment, and workers in dairy cattle farms. Foodborne Pathog. Dis. 10:731-736.

Lina, G., Y. Piémont, F. Godail-Gamot, M. Bes, M. O. Peter, V. Gauduchon, F. Vandenesch, and J. Etienne. 1999. Involvement of Panton-Valentine leukocidin-producing Staphylococcus aureus in primary skin infections and pneumonia. Clin. Infect. Dis. 29:11281132.

Luini, M., P. Cremonesi, G. Magro, V. Bianchini, G. Minozzi, B. Castiglioni, and R. Piccinini. 2015. Methicillin-resistant Staphylococcus aureus (MRSA) is associated with low within-herd prevalence of intra-mammary infections in dairy cows: Genotyping of isolates. Vet. Microbiol. 178:270-274.

Márquez-Ortiz, R. A., M. I. Álvarez-Olmos, J. A. Escobar Pérez, A. L. Leal, B. E. Castro, A. C. Mariño, E. R. Barrero, S. C. Mujica, S. Gaines, N. Vanegas, and the Research Group of Pediatric Infectious Diseases. 2014. USA300-related methicillin-resistant Staphylococcus aureus clone is the predominant cause of community and hospital MRSA infections in Colombian children. Int. J. Infect. Dis. 25:88-93.

McDougal, L. K., C. D. Steward, G. E. Killgore, J. M. Chaitram, S. K. McAllister, and F. C. Tenover. 2003. Pulsed-field gel electrophoresis typing of oxacillin-resistant Staphylococcus aureus and staphylococcal enterotoxins isolates from the United States: Establishing a national database. J. Clin. Microbiol. 41:5113-5120.

Normanno, G., M. Corrente, G. La Salandra, A. Dambrosio, N. C. Quaglia, A. Parisi, G. Greco, A. L. Bellacicco, S. Virgilio, and G. V. Celano. 2007. Methicillin-resistant Staphylococcus aureus and staphylococcal enterotoxins (MRSA) in foods of animal origin product in Italy. Int. J. Food Microbiol. 117:219-222.

Ogata, K., H. Narimatsu, M. Suzuki, W. Higuchi, T. Yamamoto, and H. Taniguchi. 2012. Commercially distributed meat as a potential vehicle for community-acquired methicillin-resistant Staphylococcus aureus. Appl. Environ. Microbiol. 78:2797-2802.

Petersen, A., M. Stegger, O. Heltberg, J. Christensen, A. Zeuthen, L. K. Knudsen, T. Urth, M. Sorum, L. Schouls, J. Larsen, R. Skov, and A. R. Larsen. 2013. Epidemiology of methicillin-resistant Staphylococcus aureus carrying the novel mecC gene in Denmark corroborates a zoonotic reservoir with transmission to humans. Clin. Microbiol. Infect. 19:E16-E22.

Pires, S. M., A. R. Vieira, E. Perez, D. Lo Fo Wong, and T. Hald. 2012. Attributing human foodborne illness to food sources and water in Latin America and the Caribbean using data from outbreak investigations. Int. J. Food Microbiol. 152:129-138. 
Planet, P. J., S. J. LaRussa, A. Dana, H. Smith, A. Xu, C. Ryan, A.-C. Uhlemann, S. Boundy, J. Goldberg, A. Narechania, R. Kulkarni, A. J. Ratner, J. A. Geoghegan, S.-O. Kolokotronis, and A. Prince. 2013. Emergence of the epidemic methicillin-resistant Staphylococcus aureus strain USA300 coincides with horizontal transfer of the arginine catabolic mobile element and spe $G$-mediated adaptations for survival on skin. MBio 4:e00889-13.

Reyes, J., S. Rincón, L. Díaz, D. Panesso, G. A. Contreras, J. Zurita, C. Carrillo, A. Rizzi, M. Guzmán, J. Adachi, S. Chowdhury, B. E. Murray, and C. A. Arias. 2009. Dissemination of methicillinresistant Staphylococcus aureus USA300 sequence type 8 lineage in Latin America. Clin. Infect. Dis. 49:1861-1867.

Rizek, C. F., M. H. Matté, M. Dropa, E. M. Mamizuka, L. M. de Almeida, N. Lincopan, G. R. Matté, P. M. L. Germano, M. H. Matte, M. Dropa, E. M. Mamizuka, L. M. de Almeida, N. Lincopan, G. R. Matte, and P. M. L. Germano. 2011. Identification of Staphylococcus aureus carrying the $m e c A$ gene in ready-to-eat food products sold in Brazil. Foodborne Pathog. Dis. 8:561-563.

Rodríguez-Lázaro, D., J. Ariza-Miguel, M. Diez-Valcarce, I. Fernández-Natal, M. Hernández, and J. Rovira. 2015. Foods confiscated from non-EU flights as a neglected route of potential methicillinresistant Staphylococcus aureus and staphylococcal enterotoxins transmission. Int. J. Food Microbiol. 209:29-33.

Seo, K. S., and G. A. Bohach. 2013. Staphylococcus aureus. Pages 547-573 in Food Microbiology: Fundamentals and Frontiers. M. P. Doyle and L. R. Beuchat, ed. ASM Press, Washington, DC.
Shopsin, B., M. Gomez, S. O. Montgomery, D. H. Smith, M. Waddington, D. E. Dodge, D. A. Bost, M. Riehman, S. Naidich, and B. N. Kreiswirth. 1999. Evaluation of protein A gene polymorphic region DNA sequencing for typing of Staphylococcus aureus and staphylococcal enterotoxins strains. J. Clin. Microbiol. 37:3556-3563.

Smyth, R. W., G. Kahlmeter, L. B. Olsson, and B. Hoffman. 2001. Methods for identifying methicillin resistance in Staphylococcus aureus. J. Hosp. Infect. 48:103-107.

Tenover, F. C., and R. V. Goering. 2009. Methicillin-resistant Staphylococcus aureus strain USA300: Origin and epidemiology. J. Antimicrob. Chemother. 64:441-446.

Vandenesch, F., T. Naimi, M. C. Enright, G. Lina, G. R. Nimmo, H. Heffernan, N. Liassine, M. Bes, T. Greenland, M. E. Reverdy and J. Etienne. 2003. Community-acquired methicillin-resistant Staphylococcus aureus carrying Panton-Valentine leukocidin genes: Worldwide emergence. Emerg. Infect. Dis. 9:978-984.

Vanegas López, M. C., J. E. Moreno, V. R. Rueda, J. S. Chirivi, A. Garzón, S. A. Arévalo, M. F. Martínez, P. A. Gardeazábal, and C. Baquero. 2012. Methicillin-resistant Staphylococcus aureus (MRSA) isolated from Colombian foods. BIO 2:61-67.

Virgin, J. E., T. M. Van Slyke, J. E. Lombard, and R. N. Zadoks. 2009. Short communication: Methicillin-resistant Staphylococcus aureus detection in US bulk tank milk. J. Dairy Sci. 92:4988-4991.

Weber, J. T. 2005. Community-associated methicillin-resistant Staphylococcus aureus. Clin. Infect. Dis. 41:S269-S272. 